\title{
Numerical Analysis of Free-Surface Flows over Rubber Dams
}

\author{
Chia-Ren Chu ${ }^{1, *(D)}$, Truc Thi Thu Tran ${ }^{1}$ and Tso-Ren $W u^{2}$ (D) \\ 1 Department of Civil Engineering, National Central University, 300 Jhong-Da Road, Jhong-Li, \\ Taoyuan 32001, Taiwan; ttruc667@gmail.com \\ 2 Institute of Hydrological and Oceanic Science, National Central University, 300 Jhong-Da Road, Jhong-Li, \\ Taoyuan 32001, Taiwan; tsoren@ncu.edu.tw \\ * Correspondence: crchu@cc.ncu.edu.tw; Tel.: +886-3-4227151; Fax: +886-3-4252960
}

\section{check for}

updates

Citation: Chu, C.-R.; Tran, T.T.T.; Wu, T.-R. Numerical Analysis of Free-Surface Flows over Rubber Dams. Water 2021, 13, 1271. https:// doi.org/10.3390/w13091271

Academic Editor: Renzo Rosso

Received: 28 February 2021

Accepted: 22 April 2021

Published: 30 April 2021

Publisher's Note: MDPI stays neutral with regard to jurisdictional claims in published maps and institutional affiliations.

Copyright: (c) 2021 by the authors. Licensee MDPI, Basel, Switzerland. This article is an open access article distributed under the terms and conditions of the Creative Commons Attribution (CC BY) license (https:/ / creativecommons.org/licenses/by/ $4.0 /)$.

\begin{abstract}
This study integrates a large eddy simulation (LES) model and volume of fluid (VOF) method to simulate the free-surface flows over inflexible circular-crested dams of different shapes. The simulated water depths and pressures on the dam surface are validated by the results of laboratory experiments. Then the numerical model examines the effects of the water depths and the Reynolds number on the hydrodynamic force and the discharge coefficient. The simulation results reveal that the time-averaged drag coefficient decreases as the downstream water depth $\mathrm{H}_{2}$ increases, while the influence of water depth $\mathrm{H}_{2}$ on the lift coefficients is less significant. Furthermore, the discharge coefficients of circular and elliptical dams, computed from the simulated velocity profiles over the crest of the dam, agree with the formulae suggested by previous studies when the downstream depth $\mathrm{H}_{2} / \mathrm{H}_{1}<0.90$. In contrast, the discharge coefficient of a tear-shape dam is slightly larger than those of circular dams.
\end{abstract}

Keywords: rubber dam; large eddy simulation; drag coefficient; lift coefficient; discharge coefficient

\section{Introduction}

Circular-crested low-head dams, such as rubber dams, are widely used around the world for water supply, irrigation, flood control, scour protection, and tidal barrier [1,2]. The advantages of this kind of dam are low construction cost, easy installation, and they can be used for flow measurement. In recent years, interest in using rubber dams in developing countries has substantially grown as the rubber membrane became more durable [3]. Nevertheless, rubber dams that are installed on a rigid base of the channel bed could still be damaged by torrential flows [4]. Therefore, hydrodynamic loading is one of the essential parameters in the design of rubber dams.

The rubber dam can be classified as air- and water-inflatable dams. The major advantages of air-inflatable rubber dams are short construction time and fast filling the dam by air pumps. The disadvantage of an air-inflatable dam is flow-induced vibration is more severe than the water-inflatable dam, owing to the light-weight of air. Hence, the air-inflatable dam needed to be deflated before floods. The cost of a water-inflatable rubber dam is higher than an air-inflatable dam but still lower than a traditional dam. The major advantages of water-inflatable dams are more unyielding and minimal vibration.

$\mathrm{Wu}$ and Plaut [5] used a two-dimensional boundary element method to examine the vibration and stability of an inflatable rubber dam and discovered that the equilibrium state of a circular dam is unstable if the structural damping is too small. Chanson [4] reviewed deflated and inflated rubber dams in several unstable flow conditions and demonstrated that the structural design of the rubber dam must consider the fluid-structure instability to avoid the damage.

Chanson [6] mentioned that the nappe adherence at the downstream side of the rubber dam might lead to flow instability and failure of the dam. Chanson [7] analyzed the wall pressure distribution and nappe trajectory of circular dams with deflectors and found 
that the deflectors can reduce the adherence pressure and avoid the dams' instability. Hager $[8,9]$ measured the velocity profiles at the crest of a circular weir and suggested a formula for the discharge coefficient. Ramamurthy et al. [1] applied a momentum analysis to study the discharge coefficient of the circular-crested weir and compared the results of the flume experiment. Chanson and Montes [10] used flume experiments to examine the influence of inflow conditions on the discharge coefficients of circular-crested weirs. Their results indicated that the upstream ramp did not affect the discharge coefficient and energy dissipation; however, the inflow condition has a substantial impact on the flow properties at the crest of circular weirs.

Heidarpour and Chamani [11] employed potential flow theory to derive the velocity profile and discharge coefficients of different types of circular weirs. They verified their model with the results of flume experiments. Bagheri and Heidarpour [12] used an irrotational vortex theory to determine the effects of the circulation and weir curvature on the discharge rate over circular-crested weirs and suggested a new formula for the discharge coefficient.

Schmocker et al. [13] used flume experiments to study the discharge coefficient of circular-crested weirs with various combinations of upstream and downstream angles. Their results indicated that the upstream weir face angle has only a small effect on the discharge coefficient; however, the discharge coefficient increased significantly as the downstream weir face angle increased. Naghavi et al. [14] used a computational fluid dynamics (CFD) model to simulate the pressure and velocity distributions of circular weirs. Their results show that the locations of critical flow and nappe separation depend on the weir size and inflow conditions. Cheraghi-Shirazi et al. [15] used a three-dimensional numerical model to analyze the fluid-structure interaction of an inflatable rubber dam under different flow conditions and internal pressures and concluded that the discharge coefficient is dependent on the upstream water depth and foot width of the dam.

Yuce et al. [16] used a Reynolds stress turbulence model to study the flows over cylindrical weirs of different diameters and inclination angles. Their simulation results showed that the flow pattern was affected by the inclination angle to the flow direction and that the increment of inclination angle increased the downstream velocity, thus increasing the absolute value of the negative pressure at the inward end of the weir. CheraghiShirazi et al. [17] used a fluid-structure interaction approach to study flexible rubber dams, and their results indicated that the hydraulic flow characteristics over the equilibrium shape of the flexible rubber dam are analogous to those of the rigid circular-crested weirs.

The above experimental and numerical studies focused on the flow pattern and discharge coefficient of circular rubber dams. They did not provide the essential drag and lift coefficients for the structural design of the rubber dams. Moreover, the effect of the dam shape on the discharge rate needs to be considered. This study employs a large eddy simulation (LES) model and the volume of fluid (VOF) method to investigate the hydrodynamic loading and discharge rate of circular-crested dams of different shapes. A series of numerical simulations examine the effects of the water depth and Reynolds number on the hydrodynamic loads and the discharge coefficients of the circular, elliptical, and tear-shape dams.

\section{Numerical Model}

This study used two- and three-dimensional large eddy simulation (LES) models to simulate the free-surface flows over inflexible, circular dams of different shapes. The fluid motion was simulated by solving the filtered continuity equation and the Navier-Stokes equations [18,19]:

$$
\begin{gathered}
\frac{\partial \overline{u_{i}}}{\partial x_{i}}=0 \\
\frac{\partial \rho \overline{u_{i}}}{\partial t}+\frac{\partial \rho \overline{u_{i} u_{j}}}{\partial x_{j}}=-\frac{\partial \bar{P}}{\partial x_{i}}+\rho g \delta_{i 3}+\frac{\partial}{\partial x_{j}}\left[\mu_{e f f}\left(\frac{\partial \overline{u_{i}}}{\partial x_{j}}+\frac{\partial \overline{u_{j}}}{\partial x_{i}}\right)\right]
\end{gathered}
$$


where $u$ is the fluid velocity; $P$ is the pressure; the over-bar represents that the quantity is the spatially filtered value [20]; subscripts $i, j=1,2,3$ represent the $x, y, z$ directions, respectively; $t$ is the time; $\rho$ is the density of the fluid; $g$ is the gravitational acceleration; $\delta$ is the Kronecker delta; and $\mu_{\text {eff }}$ is the effective viscosity, defined as:

$$
\mu_{\mathrm{eff}}=\mu+\mu_{S G S}
$$

where $\mu$ is the dynamic viscosity of the water, and $\mu_{S G S}$ is the viscosity of the sub-grid scale turbulence. In this study, the sub-grid scale turbulence was modeled using the dynamic model of Lilly-Smagorinsky [21]:

$$
\mu_{S G S}=\rho\left(C_{S} \Delta_{S}\right)^{2}\left[2 \bar{S}_{i j} \bar{S}_{i j}\right]^{1 / 2}
$$

where $C_{s}$ is the Smagorinsky coefficient, $S_{i j}$ is the filtered rate of strain tensor [22]:

$$
\bar{S}_{i j}=\frac{1}{2}\left(\frac{\partial \overline{u_{i}}}{\partial x_{j}}+\frac{\partial \overline{u_{j}}}{\partial x_{i}}\right)
$$

and $\Delta_{\mathrm{S}}$ is the characteristic length of the spatial filter. For two- and three-dimensional flows, the characteristic length is calculated, respectively, as:

$$
\begin{gathered}
\Delta_{\mathrm{s}}=2(\Delta \mathrm{x} \Delta \mathrm{z})^{1 / 2} \\
\Delta_{\mathrm{s}}=(\Delta \mathrm{x} \Delta \mathrm{y} \Delta \mathrm{z})^{1 / 3}
\end{gathered}
$$

where $\Delta x, \Delta y$, and $\Delta \mathrm{z}$ are the grid size in the $\mathrm{x}, \mathrm{y}$, and $\mathrm{z}$ directions. In this study, the value of the Smagorinsky coefficient was set as $C_{s}=0.30$ for two-dimensional flows and $\mathrm{C}_{\mathrm{s}}=0.15$ for three-dimensional flows. In addition, the projection method [23] was used to decouple the velocity and pressure in the Navier-Stokes equations and to solve the Poisson pressure equation (PPE). For the unsteady flow simulation, the time derivative term used the forward difference scheme.

The kinematics of the water surface was solved by the volume of fluid (VOF) method [24]. The volume fraction $f_{m}$ occupied by the water in a grid cell can be described by:

$$
\frac{\partial f_{m}}{\partial t}+\frac{\partial}{\partial x_{j}}\left(f_{m} \overline{u_{j}}\right)=0
$$

The computational cell is full of water when the volume fraction $f_{m}=1$, and the cell is partially occupied by water when $0<f_{m}<1$. The wall function is used to calculate the velocity near the channel bed:

$$
\begin{gathered}
\frac{U(z)}{u_{*}}=\frac{1}{\kappa} \ln \left(z^{+}\right)+A \\
z^{+}=\frac{z u_{*}}{v}
\end{gathered}
$$

where $z$ is the vertical distance from the channel bed to the cell center; $\kappa(=0.41)$ is the von Karman constant; $u *$ is the shear velocity; and the coefficient $A=17$, as suggested by Cabot and Moin [25]. Based on the velocity profile upstream of the dam, the friction velocity can be calculated as $u_{*}=0.0074 \mathrm{~m} / \mathrm{s}$. The grid size near the channel bed is about $\Delta z=2 \mathrm{~mm}$ for Grid 2. Therefore, the distance from the channel bed to the cell center closest to the bed is $z=\Delta z / 2=1 \mathrm{~mm}$, and the dimensionless distance $z^{+}=z \mathcal{u} * / v=7.4$.

The numerical solver was modified from the open-source software Truchas, which was developed by Los Alamos National Laboratory [26]. The same code has been used to study liquid sloshing in a baffled tank [27], free-surface flows over rectangular bridge deck [28], circular pipeline [29], and cylinder array [30]. In this study, the convergence 
criterion was set as $10^{-6}$ for the momentum equation. The Courant number was set as $\mathrm{Cr}=0.85$, and the average time step was $\Delta \mathrm{t}=9.0 \times 10^{-4} \mathrm{~s}$. The simulation results before the dimensionless time $\tau=t V_{1} / D_{1}=15$ (normalized by the upstream velocity $V_{1}$ and the diameter $D_{1}$ of the circular dam) were discarded to exclude the initial transient results from the numerical simulation. The time-averaged velocity and pressure were calculated from the simulation results between the dimensionless time $\tau=15-30$.

\section{Model Validation}

The accuracy of the present large eddy simulation (LES) model was checked by comparing the simulation results with that of flume experiments. The laboratory experiments were conducted in a circulating water flume with a rectangular cross-section $(1.10 \mathrm{~m}$ in length, $0.12 \mathrm{~m}$ in width). A smooth, circular cylinder (diameter $D_{1}=0.076 \mathrm{~m}$, width $W=0.12 \mathrm{~m}$ ) was installed in the middle of the flume (see Figures 1 and 2). The discharge rate $Q$ was measured by a $90^{\circ} \mathrm{V}$-notch weir. The water depths were measured along the centreline of the flume by a point gauge with a resolution of $0.1 \mathrm{~mm}$.

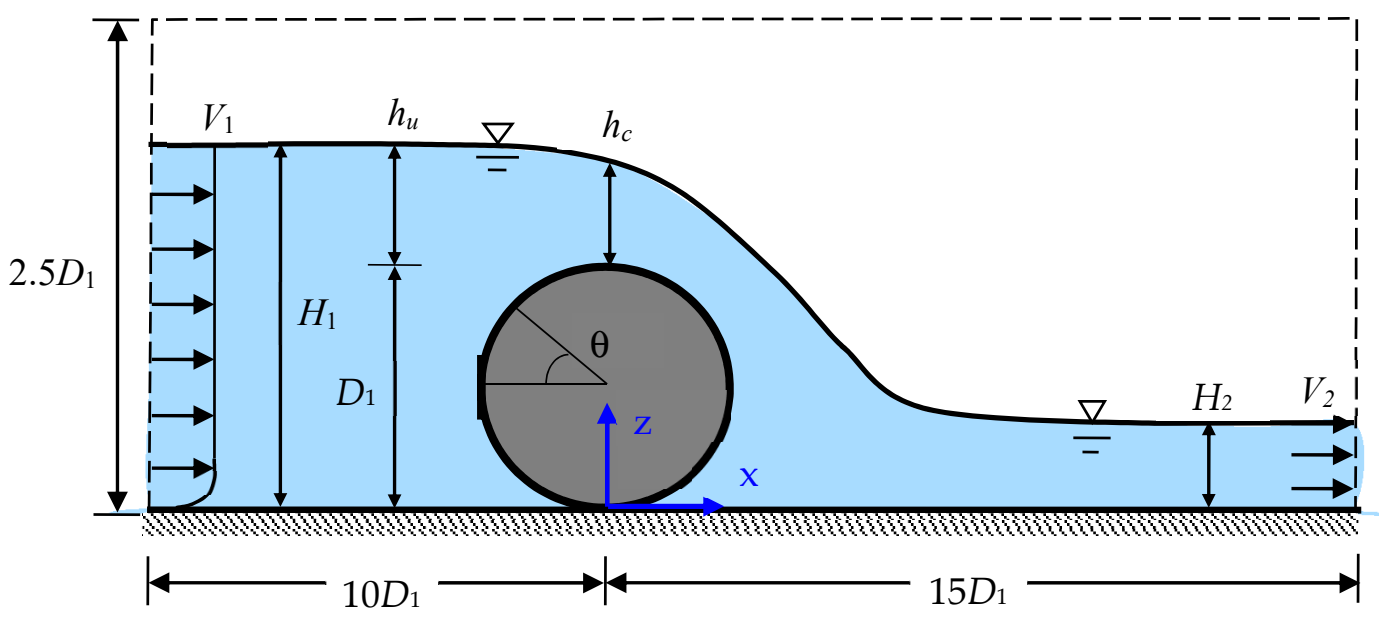

Figure 1. Schematic diagram of the circular dam and flow parameters.

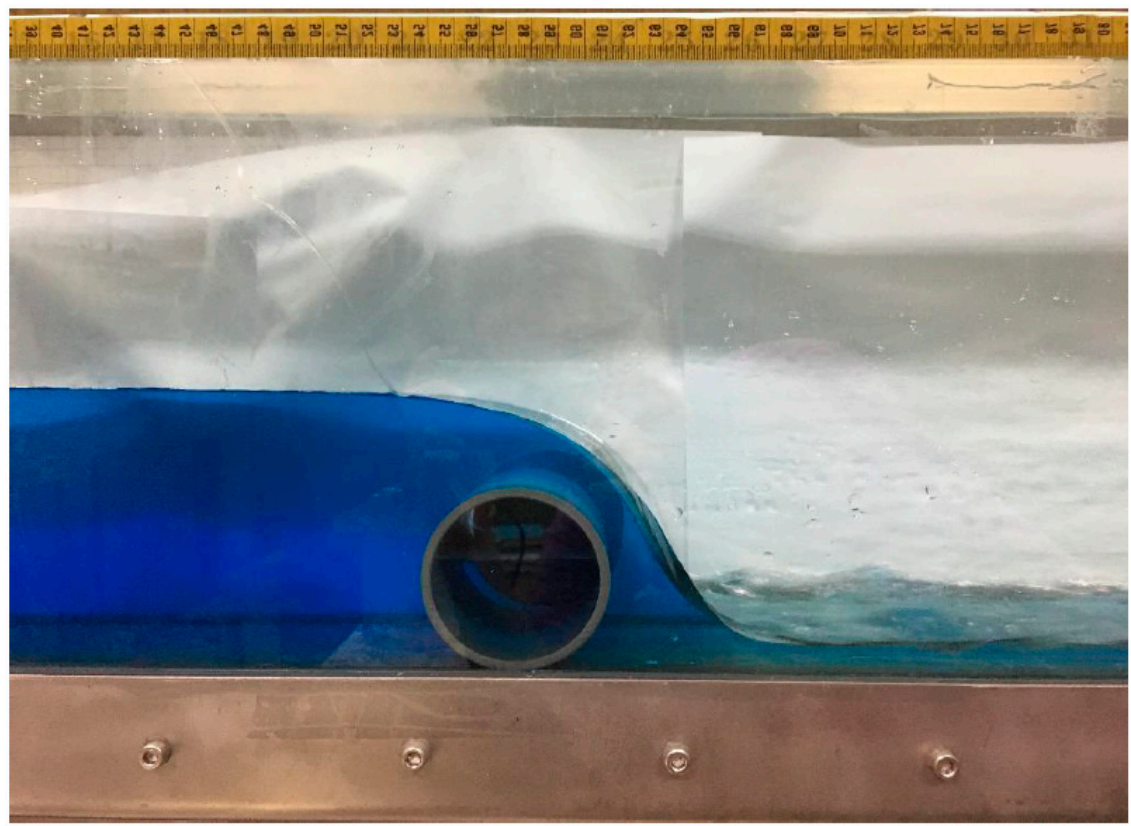

Figure 2. Photograph of the circular dam model in the flume experiment. 
In the flume experiment, the upstream and downstream water depth were $H_{1}=0.109 \mathrm{~m}$ $=1.44 D_{1}$ and $H_{2}=0.0104 \mathrm{~m}=0.137 D_{1}$, respectively. The upstream velocity $V_{1}=0.115 \mathrm{~m} / \mathrm{s}$, the upstream Froude no. $F r_{1}=V_{1} /\left(g H_{1}\right)^{1 / 2}=0.11$, and the Reynolds number $\operatorname{Re}=V_{1} D_{1} / v$ $=8740$.

Figure 3 shows the computational domain and grid arrangement. The entire computational domain was divided into 10 zones, and Zone VIII, where the dam was located, adopted a non-structured grid with the smallest grid size, $0.026 D_{1}$. For Zones I, VI, $\mathrm{V}$, and $\mathrm{X}$, non-uniform grids were used, and the stretching ratio was 1.04. The bottom boundary was set as the no-slip boundary condition, the lateral boundaries were set as the free-slip boundary condition, and the downstream boundary was set as zero-gradient for stream-wise velocity $[22,28]$.
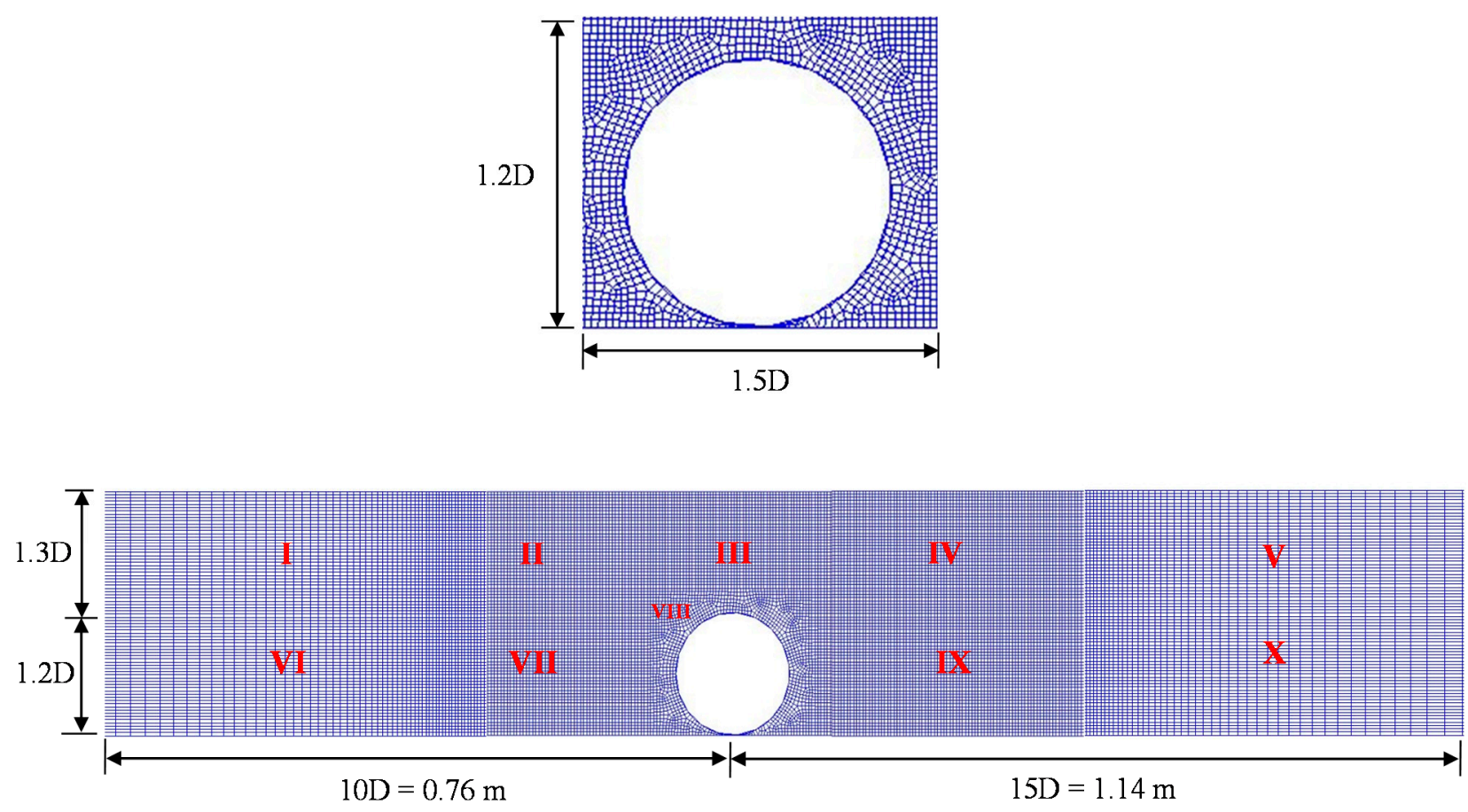

Figure 3. Computational domain and grid arrangement for the circular dam ( $\mathrm{D}$ is the diameter of the dam).

For the validation case (A1), the velocity distribution at the inlet boundary was set as:

$$
\begin{array}{rlrl}
\frac{\mathrm{V}(\mathrm{z})}{\mathrm{V}_{1}} & =\left(\frac{\mathrm{z}}{\delta}\right)^{\alpha} & \mathrm{z}<\delta \\
\mathrm{V}(\mathrm{z}) & =\mathrm{V}_{1} & \mathrm{z} \geq \delta
\end{array}
$$

where $\mathrm{V}_{1}=0.115 \mathrm{~m} / \mathrm{s}$ is the velocity outside the boundary layer; $\delta=0.1 H_{1}$ is the thickness of the boundary layer, and the exponent $\alpha=0.2$. Since the boundary layer thickness $\delta$ was much smaller than the upstream water depth, $H_{1}$, the approaching flow was close to a uniform flow. Figure 4 demonstrates that the predicted water depths $h_{p}$ by different computational grids are all very close to the measured water depth $h_{m}$. Grids 1-3 are two-dimensional grids used by the 2D LES model, while Grid 4 is a three-dimensional grid computed by the 3D LES model. The average error between the predicted and measured water depths are defined as:

$$
\Delta_{\mathrm{h}}=\frac{1}{\mathrm{n}_{\mathrm{i}=1}} \sum^{\mathrm{n}} \frac{\left|\mathrm{h}_{\mathrm{m}}\left(\mathrm{x}_{\mathrm{i}}\right)-\mathrm{h}_{\mathrm{p}}\left(\mathrm{x}_{\mathrm{i}}\right)\right|}{\mathrm{h}_{\mathrm{m}}\left(\mathrm{x}_{\mathrm{i}}\right)}
$$

where $\mathrm{n}$ is the number of measured water depth $\mathrm{h}_{\mathrm{m}}$. Table 1 summarizes the relative errors $\Delta_{\mathrm{h}}$ of different computational grids. As can be seen in Table 1, the result of the 
three-dimensional model was not outstandingly better than that of the two-dimensional models; this demonstrates that the non-uniformity of the wake flow in the y-direction (span-wise direction) did not affect the integral features on the mid-plane of the cylinder. Therefore, Grid 2 (120 grid points around the dam surface) was used for the rest of the simulation to save computing time.

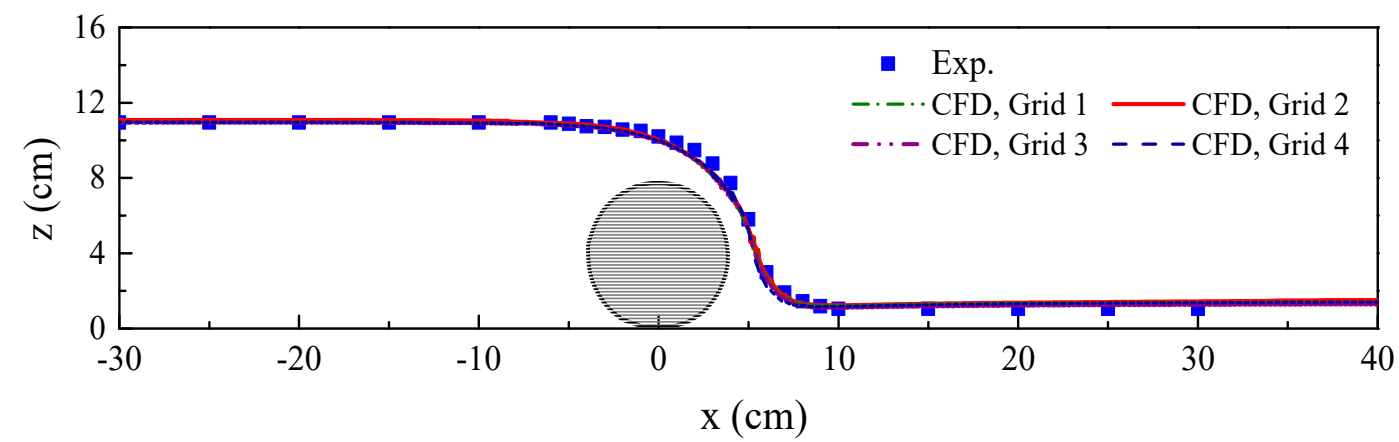

Figure 4. Comparison of measured and simulated water surfaces by different computational grids for the validation case (Case A1).

Table 1. Simulation results of the validation case by different computational grids.

\begin{tabular}{|c|c|c|c|c|c|c|c|c|}
\hline Title & \multicolumn{2}{|c|}{ Grid 1 (2D) } & \multicolumn{2}{|c|}{ Grid 2 (2D) } & \multicolumn{2}{|c|}{ Grid 3 (2D) } & \multicolumn{2}{|c|}{ Grid 4 (3D) } \\
\hline Total grid no. & \multicolumn{2}{|c|}{104,048} & \multicolumn{2}{|c|}{159,212} & \multicolumn{2}{|c|}{233,859} & \multicolumn{2}{|c|}{955,272} \\
\hline Grid no. on the cylinder surface & \multicolumn{2}{|c|}{90} & \multicolumn{2}{|c|}{120} & \multicolumn{2}{|c|}{150} & \multicolumn{2}{|c|}{120} \\
\hline $\begin{array}{l}\text { Grid size near } \\
\text { the cylinder }\end{array}$ & \multicolumn{2}{|c|}{$2.65 \mathrm{~mm}$} & \multicolumn{2}{|c|}{$2.0 \mathrm{~mm}$} & \multicolumn{2}{|c|}{$1.60 \mathrm{~mm}$} & \multicolumn{2}{|c|}{$2.0 \mathrm{~mm}$} \\
\hline Smallest grid size & \multicolumn{2}{|c|}{$\begin{array}{l}\Delta x=3 \mathrm{~mm} \\
\Delta \mathrm{z}=3 \mathrm{~mm}\end{array}$} & \multicolumn{2}{|c|}{$\begin{array}{l}\Delta x=2 \mathrm{~mm} \\
\Delta \mathrm{z}=2 \mathrm{~mm}\end{array}$} & \multicolumn{2}{|c|}{$\begin{array}{l}\Delta \mathrm{x}=1.5 \mathrm{~mm} \\
\Delta \mathrm{z}=1.5 \mathrm{~mm}\end{array}$} & \multicolumn{2}{|c|}{$\begin{array}{l}\Delta x=2 \mathrm{~mm} \\
\Delta y=5 \mathrm{~mm} \\
\Delta z=2 \mathrm{~mm}\end{array}$} \\
\hline $\begin{array}{c}\text { Water surface } \\
\Delta_{\mathrm{h}}\end{array}$ & \multicolumn{2}{|c|}{$8.53 \%$} & \multicolumn{2}{|c|}{$5.59 \%$} & \multicolumn{2}{|c|}{$5.06 \%$} & \multicolumn{2}{|c|}{$6.97 \%$} \\
\hline \multirow{2}{*}{ Force coeff. } & $C_{D}$ & $C_{L}$ & $C_{D}$ & $C_{L}$ & $C_{D}$ & $C_{L}$ & $C_{D}$ & $C_{L}$ \\
\hline & 89.7 & 95.5 & 89.6 & 88.5 & 93.1 & 93.1 & 90.3 & 97.8 \\
\hline CPU time & \multicolumn{2}{|c|}{$18 \mathrm{~h}$} & \multicolumn{2}{|c|}{$26 \mathrm{~h}$} & \multicolumn{2}{|c|}{$40 \mathrm{~h}$} & \multicolumn{2}{|c|}{$768 \mathrm{~h}$} \\
\hline
\end{tabular}

The flow parameters are: $H_{1}=0.109 \mathrm{~m}, V_{1}=0.115 \mathrm{~m} / \mathrm{s}, H_{2}=0.0104 \mathrm{~m}, V_{2}=1.21 \mathrm{~m} / \mathrm{s}$.

The pressures on the surface of the circular dam were measured by a pressure transducer (Fox, TR49). The measuring range of the transducer is 0-5000 Pa, with a resolution of $25 \mathrm{~Pa}$. The sampling duration was $100 \mathrm{~s}$, and the sampling frequency was $10 \mathrm{~Hz}$. The total pressures (including hydrostatic and dynamic pressure) on the dam surface were measured at locations $\theta=0^{\circ}, 90^{\circ}$, and $180^{\circ}$. The pressure coefficient is defined as:

$$
C_{p}=\frac{P}{\frac{1}{2} \rho V_{1}^{2}}
$$

where $P$ is the total pressure on the dam surface; $\rho$ is the density of the water; and $V_{1}$ is the undisturbed upstream velocity. The total pressure can be separated into the hydrostatic pressure $P_{\text {stat }}$ and the dynamic pressure $P_{\mathrm{d}}$.

Figure 5 compares the measured and predicted time-averaged total pressure coefficients, $C_{p}$, on the dam surface of the validation case (Case A1). The maximum pressure occurred at the location $\theta=-90^{\circ}$ due to the hydrostatic pressure was the largest near the upstream channel bed. The pressure coefficient was negative between $\theta=90^{\circ}-180^{\circ}$, owing to the large velocity on the top and leeward side of the circular dam. In addition, 
the difference between the measured and predicted time-averaged pressure coefficients by Grid 2 was $3.2-6.3 \%$. Note that the predicted pressures by the two- and three-dimensional (Grid 4) LES model were very close. The good agreement between the measured and predicted pressures validates the accuracy of the present LES model.

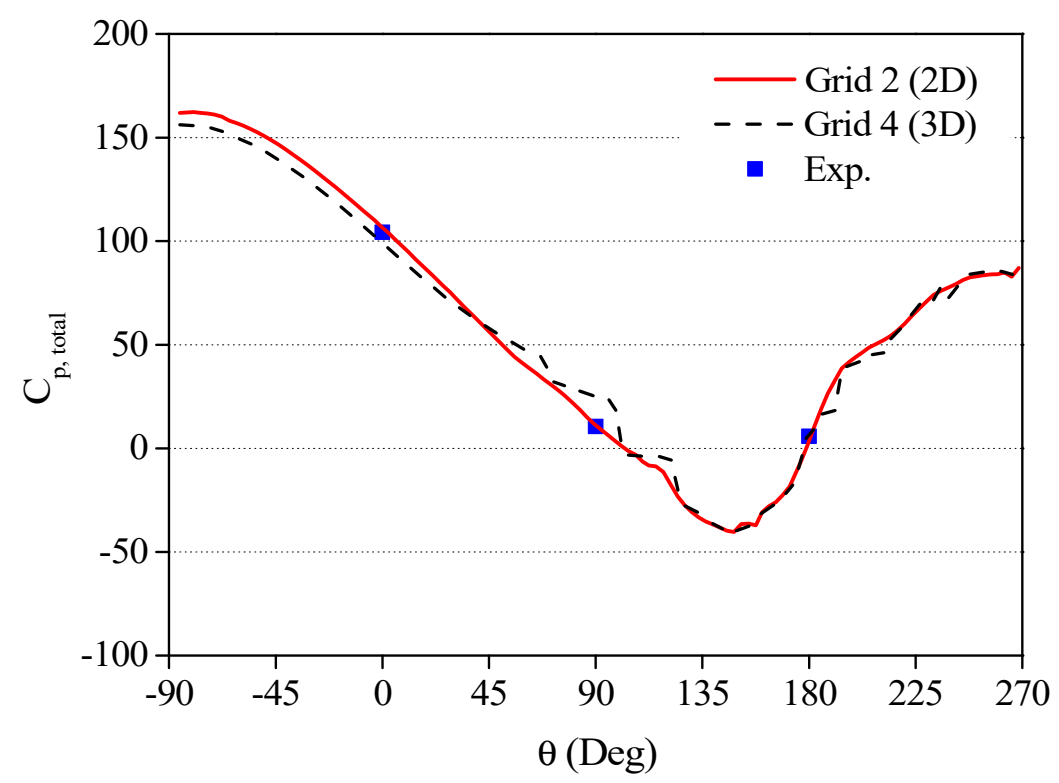

Figure 5. Comparison of measured and predicted pressure coefficients on the surface of the circular dam for the validation case (Case A1).

For the validation case, the time-averaged total and dynamic pressure coefficients on the mid-plane of the dam are shown in Figure $6 a, b$, respectively. The negative (suction) pressure on the leeward side of the dam was caused by the nappe flow over the circular dam. In addition, notice the large positive dynamic pressure on the channel bed downstream of the dam, resulting from the high-speed jet flow descending from the dam. If the channel bed were an erodible bed, scouring would occur downstream of the dam.

By neglecting the viscous stress on the dam surface, the time-averaged drag and lift of the dam were calculated from the simulated pressure on the dam surface:

$$
\begin{gathered}
F_{D}=\sum_{i=1}^{n} P\left(\theta_{i}\right) \cos \theta_{i}(W R \Delta \theta) \\
F_{L}=-\sum_{i=1}^{n} P\left(\theta_{i}\right) \sin \theta_{i}(W R \Delta \theta)
\end{gathered}
$$

where $\theta_{\mathrm{i}}$ is the angle; $n(=120)$ is the number of angular locations (grid points) on the dam surface; $R$ is the radius of the dam; and $W$ is the dam width. The dimensionless drag coefficient, $C_{D}$, is defined as:

$$
C_{D}=\frac{F_{D}}{\frac{1}{2} \rho V_{1}^{2} A}
$$

where $F_{D}$ is the drag acting on the dam, and $A=W D_{1}$ is the projected area of the circular dam. The lift coefficient, $C_{L}$, is defined as:

$$
C_{L}=\frac{F_{L}}{\frac{1}{2} \rho V_{1}^{2} A}
$$


The dimensionless buoyancy experienced by the circular dam can be calculated as:

$$
C_{B}=\frac{F_{B}}{\frac{1}{2} \rho V_{1}^{2} A}=\frac{\pi D_{1} g}{2 V_{1}^{2}}
$$

(a) Coefficient of total pressure

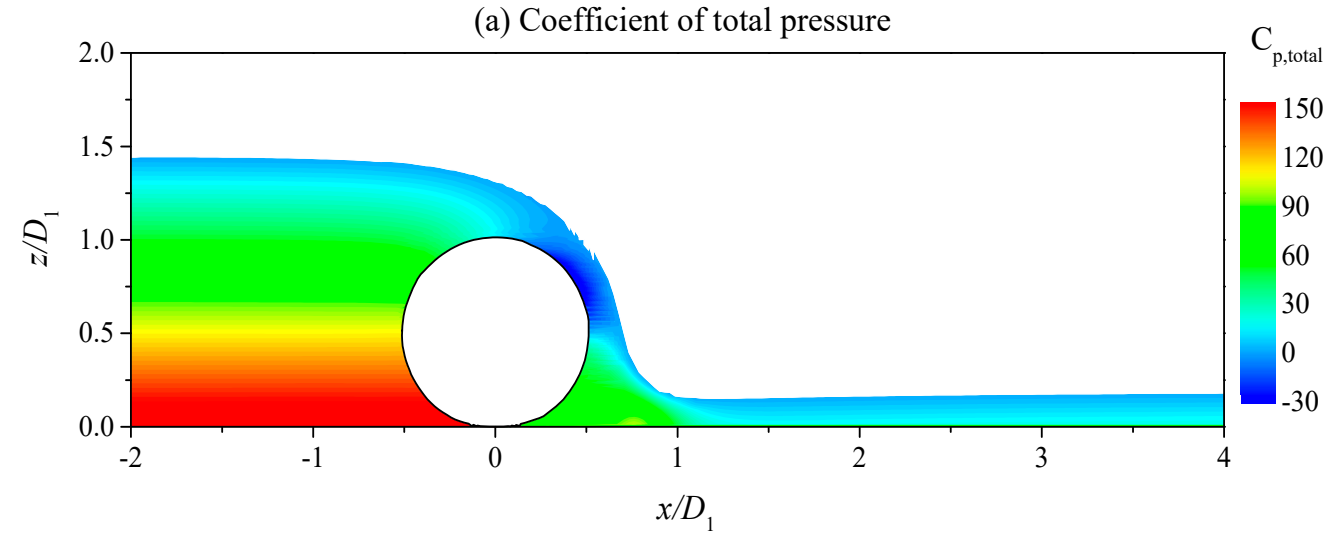

(b) Coefficient of dynamic pressure

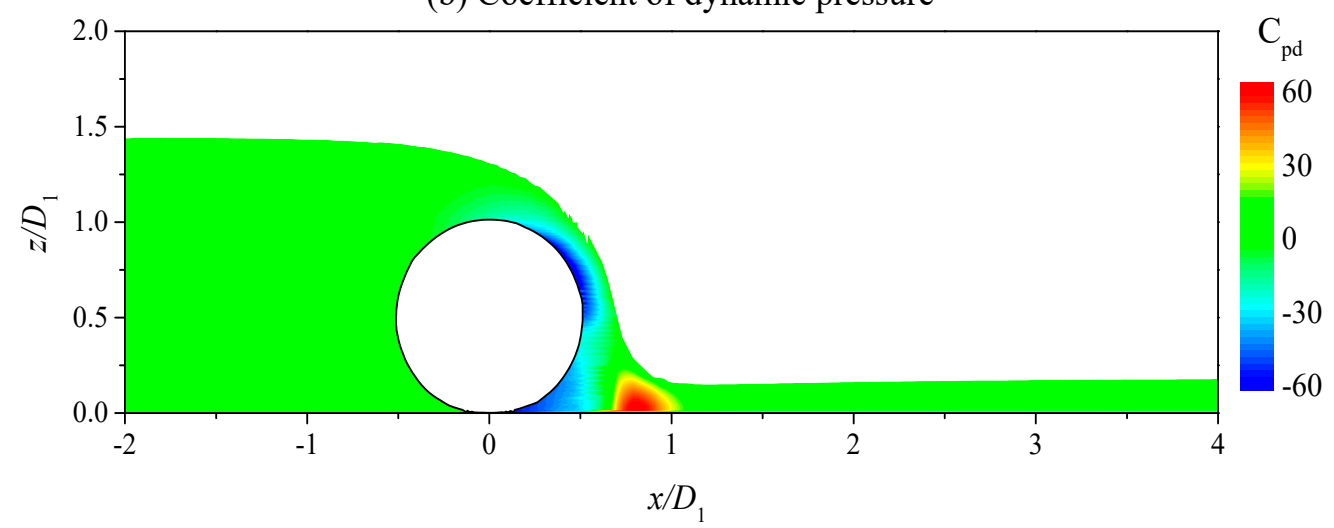

Figure 6. Distribution of pressure coefficients on the centerline of the circular dam for the validation case (Case A1). (a) Total pressure; (b) dynamic pressure.

\section{Results and Discussion}

\subsection{Hydrodynamic Loading}

The validated large eddy simulation model was used to examine the effects of the downstream water depth and Reynolds number on the hydrodynamic force and discharge coefficients of the circular dam. For Cases A1-A7, the diameter of the circular dam $D_{1}=0.076 \mathrm{~m}$, upstream water depth $H_{1}=0.109 \mathrm{~m}$, and velocity $V_{1}=0.115 \mathrm{~m} / \mathrm{s}$ were identical to that of the flume experiment. However, the downstream water depth varied in the range of $H_{2}=0.010 \mathrm{~m}-0.107 \mathrm{~m}$ (depth ratio $\mathrm{H}_{2} / \mathrm{H}_{1}=0.10-0.98$ ). Therefore, the downstream velocity $V_{2}=0.117-1.21 \mathrm{~m} / \mathrm{s}$, and the downstream Froude number was $\mathrm{Fr}_{2}=0.12-3.53$.

Figure 7 shows the variations of water depths of Case A1-Case A7 (different depth ratios $\mathrm{H}_{2} / \mathrm{H}_{1}$ ). Note that it only shows the simulated water depths in the range of $\mathrm{x} / D_{1}=-2.0-4.0$, while the downstream boundary is set at $\mathrm{x} / D_{1}=15$. When the depth ratio $H_{2} / H_{1} \leq 0.2$, the upstream flow conditions were sub-critical flows, while the downstream conditions were super-critical flows. The water surface dropped rapidly right behind the dam. As the downstream water depth $\mathrm{H}_{2}$ increased, the downstream conditions became sub-critical flows, and the water surface was disturbed by the strong turbulence behind the dam. The disturbance lessened, and the water surface gradually became smoother as it goes downstream. 


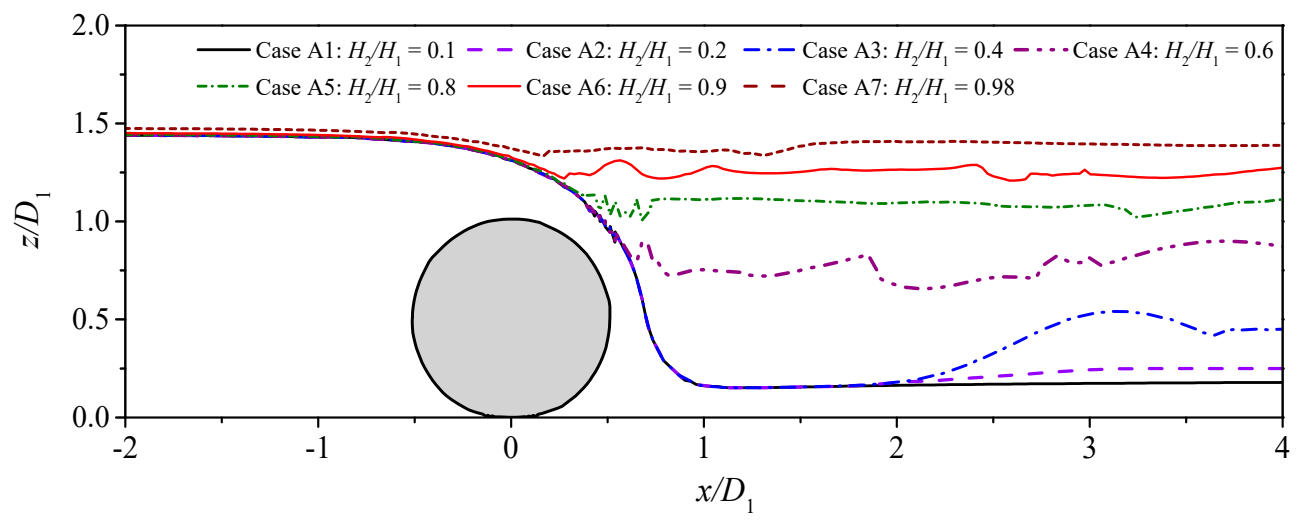

Figure 7. Variation of the water depths over the circular dam of different depth ratios for Cases A.

Figure 8 illustrates the time-averaged velocity vectors on the mid-plane of the dam for three different depth ratios, $H_{2} / H_{1}=0.2,0.6$, and 0.98 . The flow conditions distinctly differed when the water depth $H_{2}$ changed. When the depth ratio $H_{2} / H_{1}=0.2$, there was a downward jet flow on the leeward side of the dam, and the downstream was a super-critical flow. In contrast, a submerged hydraulic jump (a high-speed flow near the channel bed and a reversed flow near the water surface) occurred in the wake of the dam when $H_{2} / H_{1}=0.6$. When the depth ratio $H_{2} / H_{1}=0.98$, the water flowed horizontally over the dam, and the high-speed flow stayed close to the free surface.

Figure 9 depicts the total, $C_{p \text { total }}$, and dynamic pressure coefficients, $C_{p d}$, on the centerline of the dam surface for different depth ratios. The total and dynamic pressures on the frontal side $\left(\theta=-90^{\circ}-30^{\circ}\right)$ of the dam were identical since the upstream water depths; subsequently, the hydrostatic pressures were the same for different depth ratios. The leeward total pressures increased as the downstream depths increased owing to the hydrostatic pressure. The leeward dynamic pressures for the cases of $H_{2} / H_{1}=0.1,0.2$, and 0.4 (see Figure 9b) were identical due to the similar downstream flow conditions. The negative dynamic pressure (caused by the nappe flow) on the leeward side of the dam increased as the depth ratio $\mathrm{H}_{2} / \mathrm{H}_{1}$ decreased. Notice that the location of the maximum suction shifted from $\theta=90^{\circ}$ to $\theta=150^{\circ}$ as the depth $H_{2}$ decreased due to the change of the flow attachment. The simulated pressure distribution can be used for the structural design of the rubber dams.

Besides Equation (14), the fluid drag of the dam also can be computed by the momentum integration method. In steady, two-dimensional flows, the momentum equation of the channel flow is:

$$
\rho g \frac{H_{1}^{2}}{2} W-\rho g \frac{H_{2}^{2}}{2} W-F_{\mathrm{D}}=\rho\left[\int_{0}^{H_{2}} V_{2}^{2}(z) d A-\int_{0}^{H_{1}} V_{1}^{2}(z) d A\right]
$$

where $F_{D}$ is the drag acting upon the water flow by the dam; $V_{1}(z)$ and $V_{2}(z)$ are the stream-wise velocities up- and downstream of the dam, respectively. Assuming that the up- and downstream are both uniform flows, and the bed friction is negligible, the drag is equal to:

$$
F_{\mathrm{D}}=\frac{\rho g W}{2}\left({H_{1}}^{2}-{H_{2}}^{2}\right)+\rho Q\left(V_{1}-V_{2}\right)
$$

where the discharge rate in the channel $\mathrm{Q}=V_{1} H_{1} W=V_{2} H_{2} W$. The first term on the righthand side of Equation (20) represents the difference between the up- and downstream hydrostatic pressures, and the second term on the right-hand side is the net momentum fluxes. 
(a) Case A2: $H_{2} / H_{1}=0.20, F r_{1}=0.11, F r_{2}=1.24$

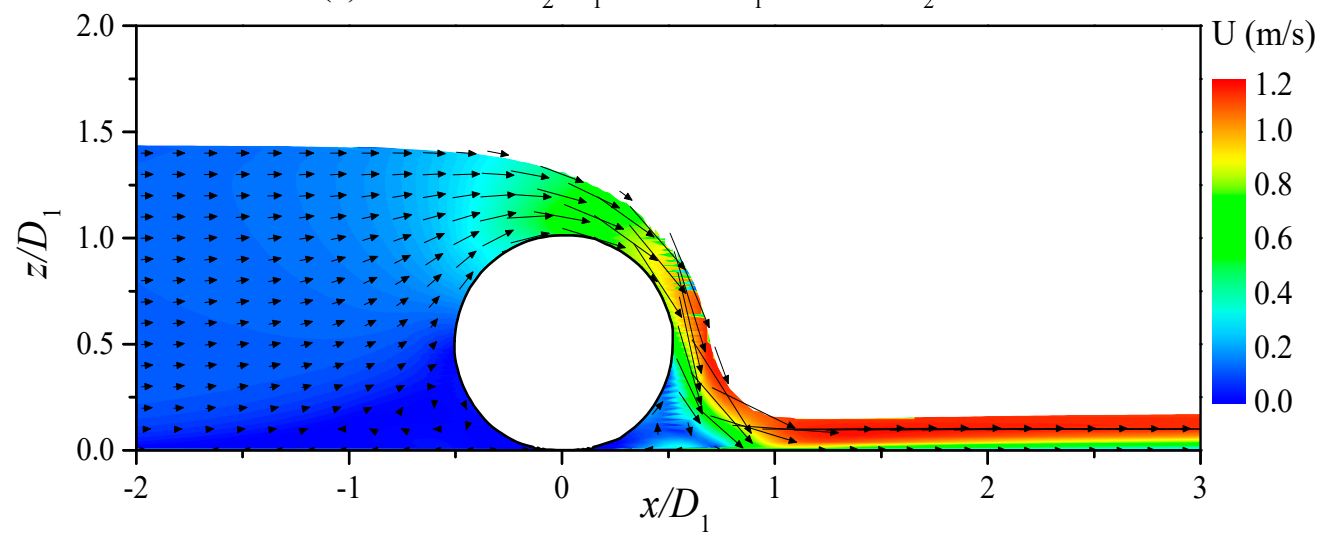

(b) Case A4: $H_{2} / H_{1}=0.60, F r_{1}=0.11, F r_{2}=0.24$

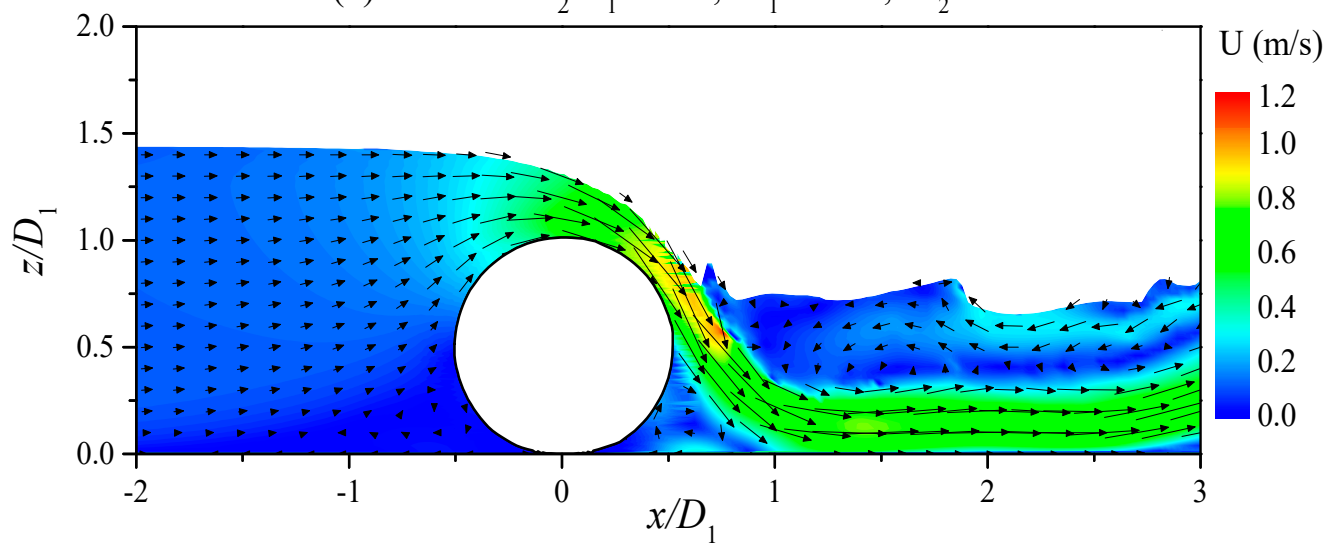

(c) Case A7: $H_{2} / H_{1}=0.98, F r_{1}=0.11, F r_{2}=0.11$

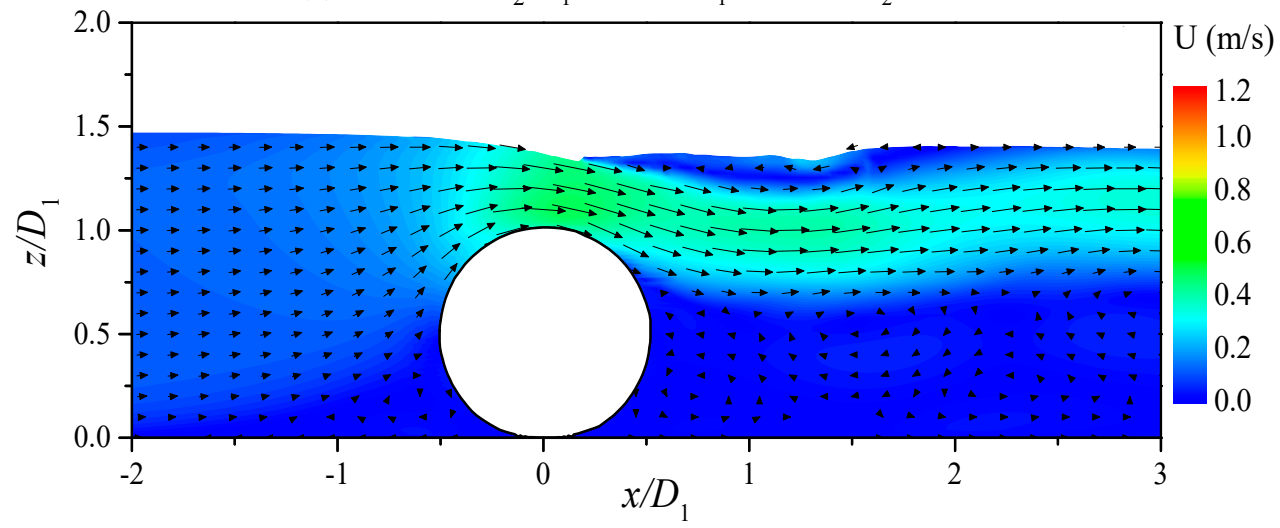

Figure 8. Time-averaged velocity vectors on the mid-plane the circular dam under different downstream depths. (a) $H_{2} / H_{1}$ $=0.2 ;(\mathbf{b}) H_{2} / H_{1}=0.6 ;(\mathbf{c}) H_{2} / H_{1}=0.98$.

The time-averaged drag coefficients, computed by Equation (20), were plotted against the depth ratio $\mathrm{H}_{2} / \mathrm{H}_{1}$ in Figure 10a. The average relative error between the drag coefficients computed by the momentum integration method and from the simulated total pressures was $6.5 \%$. This validated the present LES model to compute the drag of the dam. Notice that the drag coefficients (from the LES model) were almost the same $\left(C_{D}=89.5\right)$ when the depth ratio $H_{2} / H_{1} \leq 0.40$. This large drag was caused by the difference between the upand downstream hydrostatic pressures. When $H_{2} / H_{1}>0.40$, the drag coefficient $C_{D}$ (and the difference of hydrostatic pressure) steadily decreased with the increasing downstream water depth $\mathrm{H}_{2}$. 
(a) Total Pressure

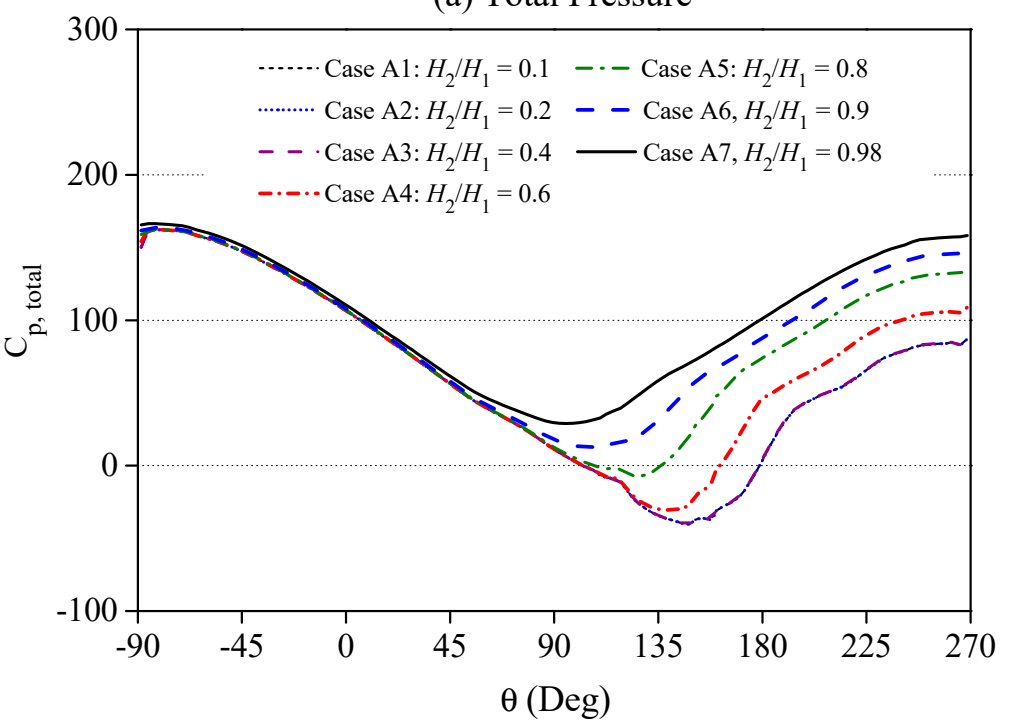

(b) Dynamic Pressure

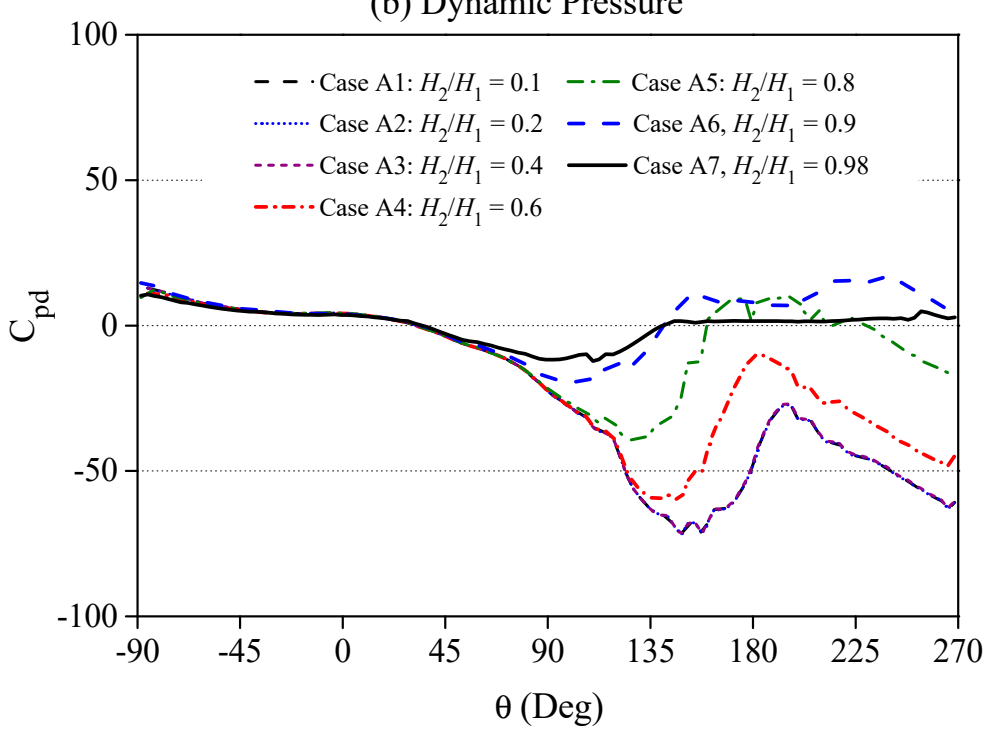

Figure 9. Pressure coefficients on the surface of the circular dam under different depth ratios. (a) Total pressure; (b) dynamic pressure.

Nonetheless, it is difficult to apply the momentum integration method to compute the lift coefficient of the dam. Figure $10 \mathrm{~b}$ reveals that the time-averaged lift coefficients, computed from the LES results, were in the range of $C_{L}=97-110$. The dimensionless buoyancy $C_{B}=88.6$ for different downstream depths; therefore, the lift coefficients without the buoyancy (without the hydrostatic pressure) $C_{L}-C_{B}=8.5-21.4$. The reason that the lift coefficients of large depth ratios $\left(\mathrm{H}_{2} / \mathrm{H}_{1}>0.60\right)$ were slightly larger than those of small depth ratios $\left(H_{2} / H_{1} \leq 0.40\right)$ is due to the maximum negative pressures occurred on the top side, rather than on the leeward side of the dam when downstream depth $\mathrm{H}_{2}$ was large.

The height of full-size prototype rubber dams is in the range of 1.0-6.0 m; hence, the Reynolds number is much larger than that of a scaled-down model dam. In order to examine the effect of Reynolds number $\operatorname{Re}=V_{1} D_{1} / v$ on the hydrodynamic loading of the circular dam, the surface pressure on a circular cross-section, with the diameter $D_{1}=3.0 \mathrm{~m}$, was simulated by the present LES model. The scale ratio of the full-size dam to the model dam is 39.5. The up- and downstream water depths were set as: $H_{1}=4.30 \mathrm{~m}$ and $H_{2}=0.41 \mathrm{~m}$; the up- and downstream velocities $V_{1}=0.45 \mathrm{~m} / \mathrm{s}$ and $V_{2}=4.72 \mathrm{~m} / \mathrm{s}$. Hence, the depth ratios, $H_{2} / H_{1}=0.095, H_{1} / D_{1}=1.43$ and the Froude number $F r_{1}=0.07$, 
were close to those of the validation case (Case A1). The upstream was a sub-critical flow, and the downstream was a super-critical flow.

(a) Drag coefficient

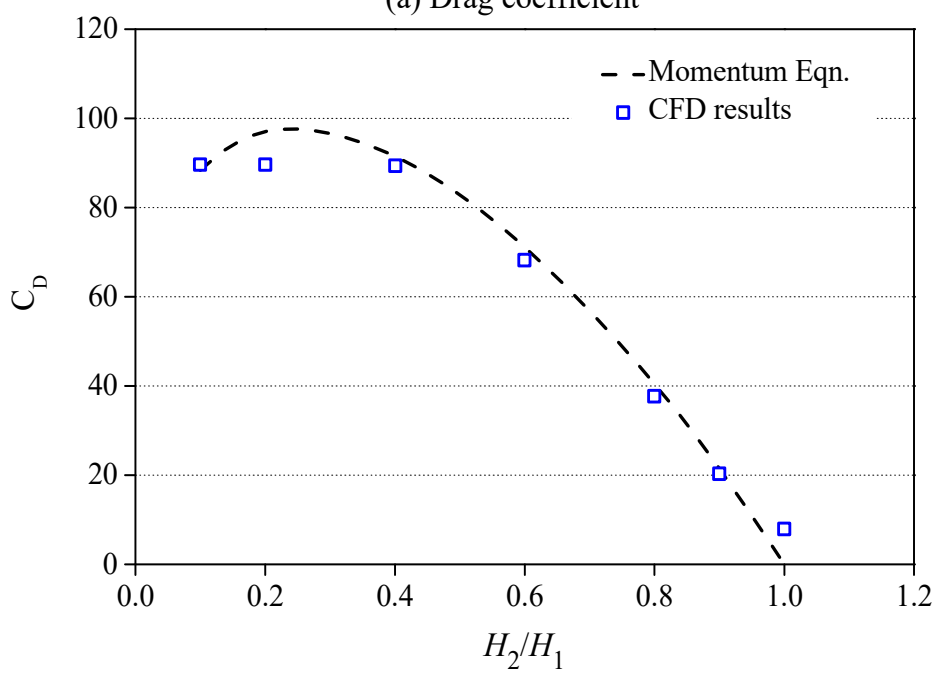

(b) Lift coefficient

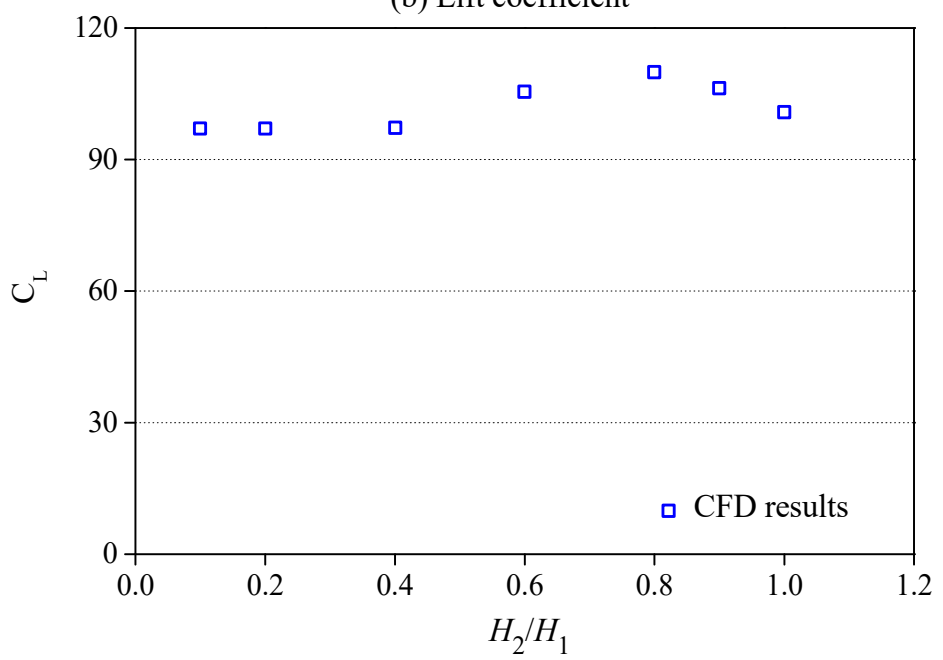

Figure 10. Relationship between the depth ratio and force coefficients (a) drag coefficient; (b) lift coefficient.

Figure 11 compares the simulated surface pressures on the centerline of the scaleddown flume model $(\operatorname{Re}=8740)$ and that of the full-size dam $\left(\operatorname{Re}=1.35 \times 10^{6}\right)$. As can be seen in Figure 11a, the total pressure in front of the full-size prototype dam was much larger than that of the scaled-down model owing to the difference in hydrostatic pressure. Figure $11 \mathrm{~b}$ illustrates that the maximum suction pressure occurred at the angular location of $145^{\circ}$ (on the leeward side of the dam). In contrast, the suction pressure of the prototype dam was much larger than that of the scaled-down model, resulting from the velocity of the nappe flow over the prototype dam was larger than that of the scaled-down model. Furthermore, the drag and lift coefficients $\left(C_{D}=249\right.$ and $\left.C_{L}=272\right)$ of the prototype dam were different from that of the scaled-down model $\left(C_{D}=89.5\right.$ and $\left.C_{L}=97\right)$. The lift coefficients without the dimensionless buoyancy were $C_{L}-C_{B}=8.5$ and 43.9 for scaled-down and prototype dam, respectively. In other words, the dimensionless force coefficients obtained from the scaled-down model experiments are not applicable to the full-size circular dams due to 
the Reynolds number effect. The present numerical model can be used to compute the dynamic loading of the full-size dams for the purpose of structural design.

(a) Total Pressure Coefficient

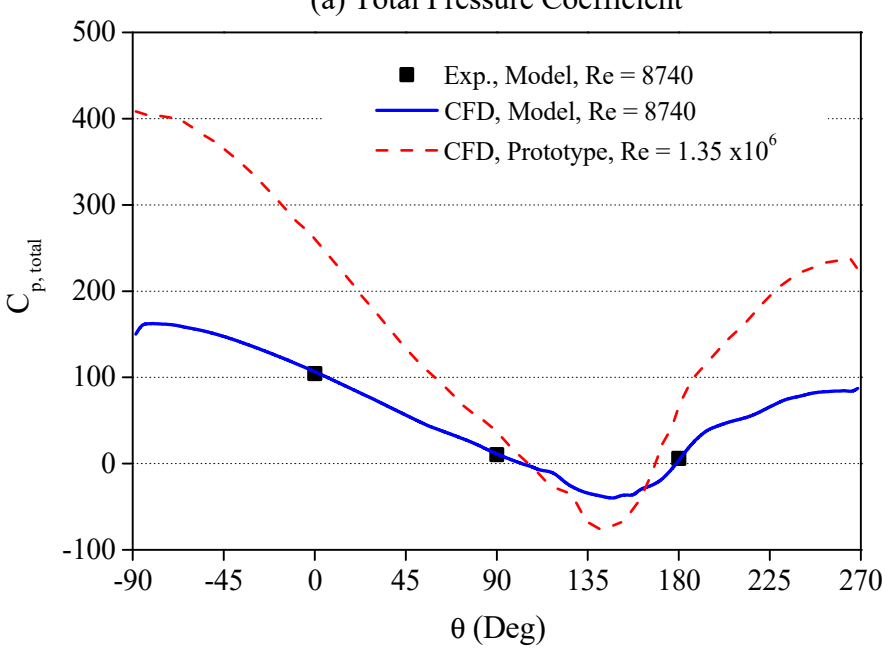

(b) Dynamic Pressure Coefficient

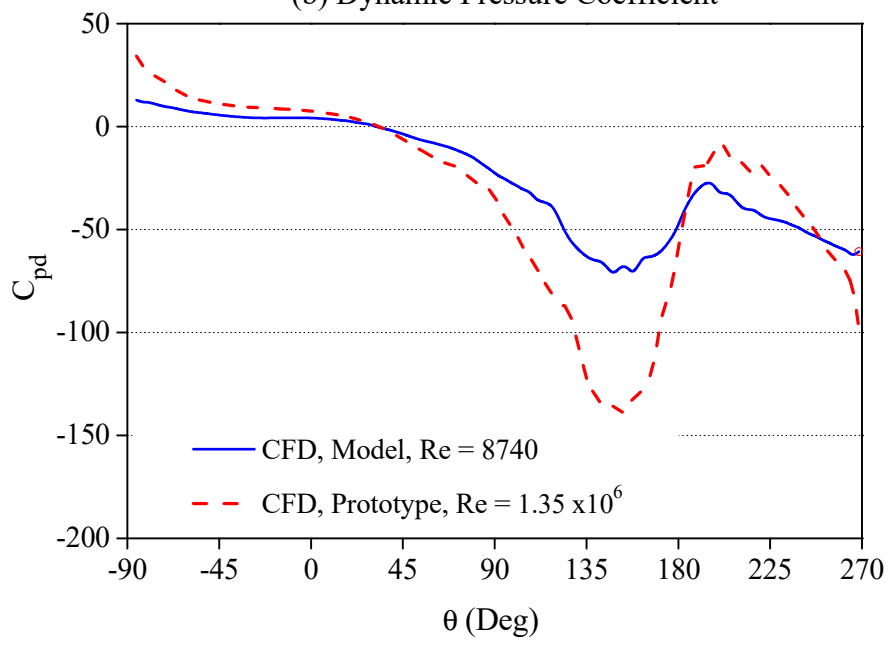

Figure 11. Comparison of simulated pressure coefficients on the surfaces of scaled-down model and prototype circular dams. (a) Total pressure; (b) dynamic pressure.

\subsection{Discharge Coefficient}

One of the advantages of circular-crested dams is they can be used for flow measurement. The profiles of time-averaged horizontal velocity above the crest $(x=0)$ of the circular dam under different depth ratios are shown in Figure 12. The velocity profiles were similar to the experimental results of Heidarpour and Chamani [11] and close to each other when the depth ratio $H_{2} / H_{1}<0.90$. Notice that the velocities, due to the boundary layer at the dam surface, decreased as it approached the dam crest. In contrast, the horizontal velocities became smaller for the depth ratio $H_{2} / H_{1}=0.90$ and 0.98 , under the same upstream flow condition. The depth-averaged velocity $V_{\mathrm{c}}$ and water depth $h_{\mathrm{c}}$ above the dam crest are used to compute the Froude number at the dam crest, $F r_{c}=V_{c} /\left(g h_{c}\right)^{0.5}=0.96$ and 0.81 when $H_{2} / H_{1}=0.90$ and 0.98 , respectively. In other words, they did not reach the critical flow condition at the dam crest. 


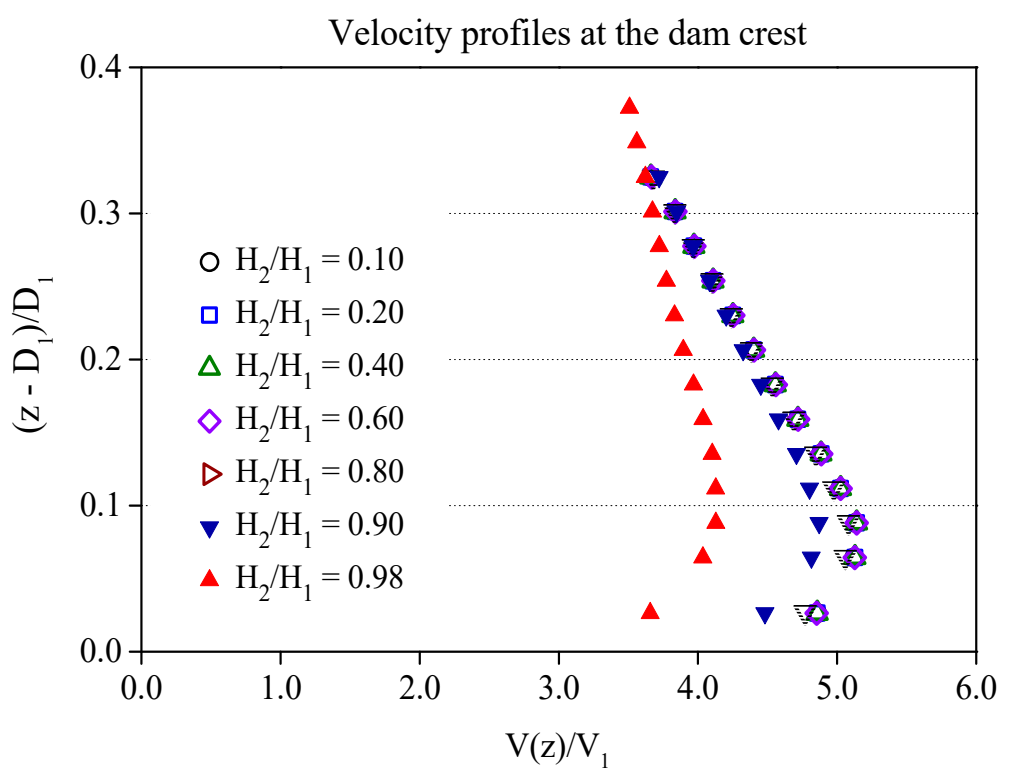

Figure 12. Profiles of time-averaged horizontal velocity above the crest $(x=0)$ of the circular dam of different depth ratios.

The discharge rates, $Q$, were computed by integrating the horizontal velocities above the dam crest. The discharge coefficient then can be computed by the following equation:

$$
C_{d}=\frac{Q}{g^{1 / 2}\left(\frac{2}{3} h_{u}\right)^{3 / 2} W}
$$

where $h_{u}$ is the upstream $\left(\mathrm{x} / D_{1}=-5\right)$ head above the dam crest. The discharge coefficients of the circular dam are plotted against the upstream head in Figure 13. The formulae suggested by Heidarpour and Chamani [11] and Matthew [31] for the discharge coefficients are also plotted in the figure for comparison. As can be seen, the discharge coefficient $C_{d}=1.18$ for $H_{2} / H_{1} \leq 0.80$ is very close to the curves suggested by Heidarpour and Chamani [11] and Matthew [31]. However, the discharge coefficients $\left(C_{d}=1.10\right.$ and 1.04) for the cases of $H_{2} / H_{1}=0.90$ and 0.98 are lower than the curves. The reduced discharge coefficient is resulting from the flow condition above the dam crest not being critical flow when $H_{2} / H_{1} \geq 0.90$. In other words, the formulae for discharge coefficients will over-estimate the discharge rate when the downstream water depth close to the upstream depth (the Froude number at the dam crest, $\left.F r_{c}<1.0\right)$.

The compressibility of an inflatable rubber dam can be analyzed by using the bulk modulus $E_{\mathrm{v}}$ of the dam body:

$$
\frac{\Delta P}{E_{v}}=-\frac{\Delta V}{V}
$$

where $\Delta \mathrm{P}$ is the pressure change, and $\Delta \forall / \forall$ is the change rate of the total volume $\forall$. If the rubber dam is water-inflatable, the bulk modulus of the dam body will be close to water $E_{\mathrm{V}}=2.19 \times 10^{9} \mathrm{~N} / \mathrm{m}^{2}$. When the pressure variation on the dam surface is $\Delta P=10,000 \mathrm{~Pa}$ (about $1 \mathrm{~m}$ depth of water over the dam), the change rate of dam volume is about $\Delta V / V=4.4 \times 10^{-6}$. If the rubber dam is air-inflatable, the bulk modulus of the dam body will be around $E_{\mathrm{v}}=1 \times 10^{5} \mathrm{~N} / \mathrm{m}^{2}$ (close to air). Under the same pressure change $\Delta P=10,000 \mathrm{~Pa}$, the change rate of the dam volume is about $\Delta V / V=10 \%$. Therefore, the dam's height will decrease due to the hydrostatic pressure, and the dam shape becomes an elliptical when water flows over the dam.

Therefore, the present numerical model is used to simulate free-surface flows over rubber dams of two different shapes. The first one is a smooth, cylindrical dam with an elliptical cross-section. The vertical diameter (height) of the elliptical dam is $D_{1}=0.076 \mathrm{~m}$, 
and the horizontal diameter $D_{2}=1.2 D_{1}=0.091 \mathrm{~m}$. The second one is a tear-shape dam, with height $D_{1}=0.076 \mathrm{~m}$ and length $L=0.114 \mathrm{~m}$, with the frontal part a concave curve and the leeward part a semi-circular shape. The upstream water depth is $0.109 \mathrm{~m}$, velocity is $0.115 \mathrm{~m} / \mathrm{s}$, and the downstream water depth is $0.0104 \mathrm{~m}$, identical to the validation case (Case A1).

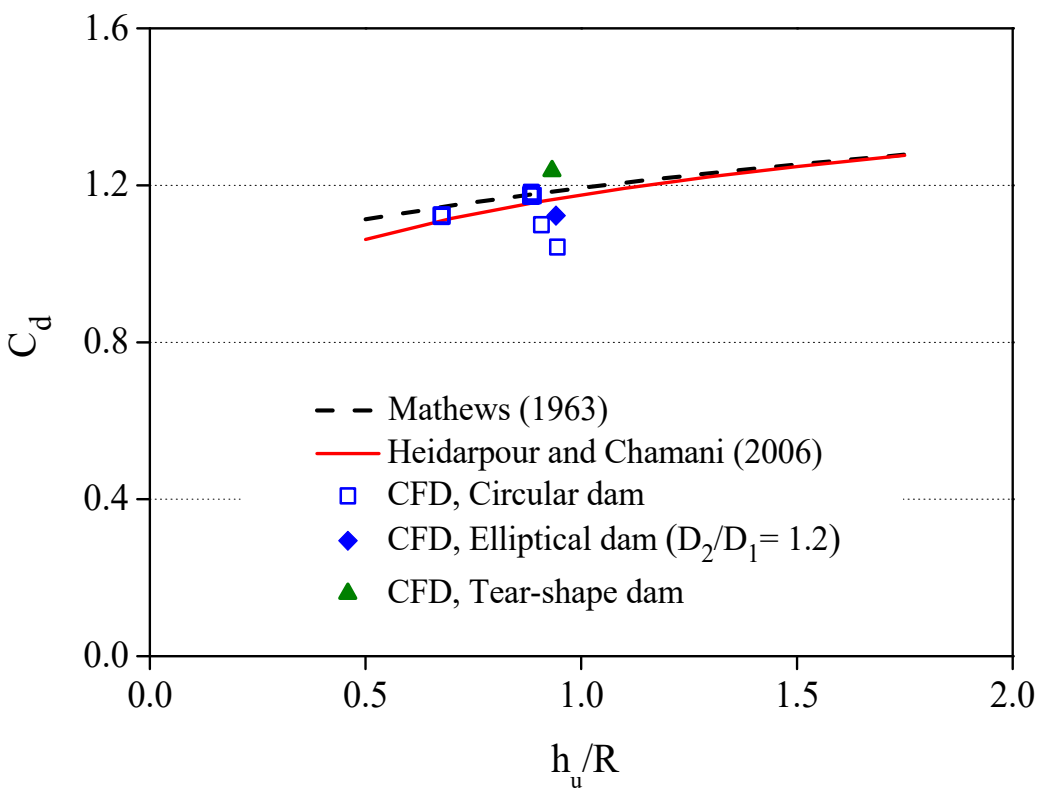

Figure 13. Relationship between the discharge coefficient and upstream water head of different dam shapes, $R=D_{1} / 2$ is the radius of the dam.

The simulated water depths over the circular dam, elliptical dam $\left(D_{2} / D_{1}=1.2\right)$, and tear-shape dam are compared in Figure 14. Due to the leeward curves of the circular and tear-shape dams are the same, the nappe flows over these two dams are quite similar. Nonetheless, the water surface on the leeward part of the elliptical dam is different from that of the circular dam. The time-averaged velocity vectors over elliptical and tear-shape dams are shown in Figure 15. As can be seen, the downstream flow fields of the elliptical and tear-shape dams are very similar. In contrast, the tear-shape dam did not have the re-circulating flows in front of the dam, such as those in the circular and elliptical dams. In other words, the tear-shape dam could prevent sediment accumulation upstream of the dam.

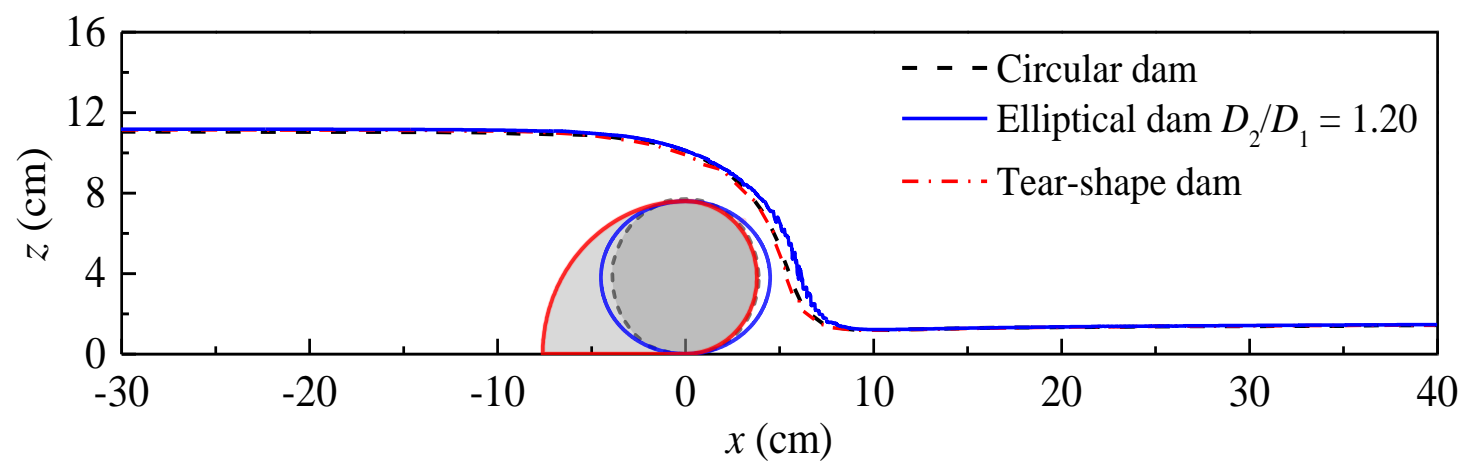

Figure 14. Comparison of the simulated water depths for the circular, elliptical, and tear-shape dams. 

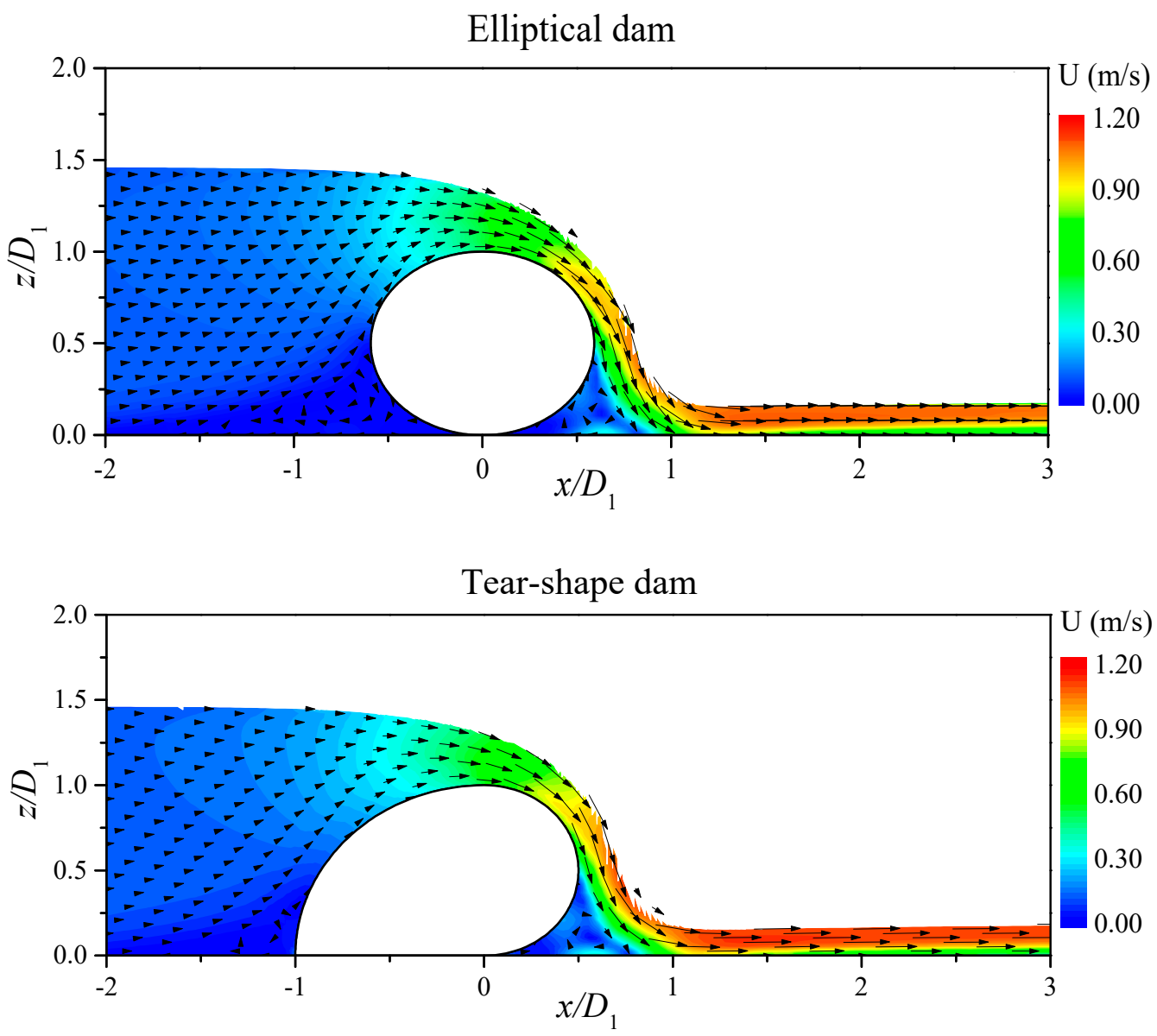

Figure 15. Time-averaged velocity vectors on the central plane of the elliptical and tear-shape dams.

\section{Concluding Remarks}

This study incorporated a large eddy simulation (LES) model and the volume of fluid (VOF) method to investigate the free-surface flows over rigid circular-crested dams of different shapes. The simulated water depth and surface pressures were validated by the results of flume experiments. The numerical model was then used to examine the influences of water depth, the Reynolds number, and dam shape on the hydrodynamic forces and discharge coefficients of circular rubber dams.

The simulation results revealed that the drag coefficient increased as the downstream water depth $\mathrm{H}_{2}$ decreased, owing to the difference in hydrostatic pressures of the upand down-stream flows. In addition, the drag coefficients calculated from the simulated surface pressures were very close to the drag coefficients computed by the momentum integration method. On the other hand, the lift coefficient increased slightly when the downstream depth $\mathrm{H}_{2}$ increased, resulting from the negative uplift pressure on the dam crest. Furthermore, the dimensionless force coefficients of full-size dams are larger than those of scaled-down dam models due to the difference in the Reynolds number.

The discharge coefficients, computed from the time-averaged velocities over the crest of the circular and elliptical dams, agree well with the formulae suggested by Hager [8] and Heidarpour and Chamani [11] when the downstream water depth $H_{2} / H_{1}<0.9$. Nevertheless, their formulae over-estimate the discharge coefficient when the downstream depth $H_{2} / H_{1} \geq 0.90$, owing to the flow condition above the dam crest not being critical flow. In addition, the discharge coefficient of the tear-shape dam is slightly larger than those of circular dams. In brief, the present numerical model can simulate the hydrodynamic loading and discharge rate of full-size rubber dams of any shape to avoid the scale effect of flume experiments. 
Author Contributions: Conceptualization, supervision, project administration, writing, review and editing, funding acquisition: C.-R.C.; Methodology and software: T.-R.W.; Validation, formal analysis, visualization, investigation: T.T.T.T.; All authors have read and agreed to the published version of the manuscript.

Funding: The funding was from the Ministry of Science and Technology (MOST) of the Republic of China, Taiwan, under grant no. 107-2221-E-008-016.

Data Availability Statement: The experimental and numerical results are available when requested.

Conflicts of Interest: The authors have no conflict of interest.

\section{References}

1. Ramamurthy, A.S.; Vo, N.-D. Characteristics of Circular-Crested Weir. J. Hydraul. Eng. 1993, 119, 1055-1062. [CrossRef]

2. Zhang, X.Q.; Tam, P.W.M.; Zheng, W. Construction, operation, and maintenance of rubber dams. Can. J. Civ. Eng. 2002, 29, 409-420. [CrossRef]

3. Saleh, A.F.M.; Mondal, M.S. Performance evaluation of rubber dam projects of Bangladesh in irrigation development. Irrig. Drain. 2001, 50, 237-248. [CrossRef]

4. Chanson, H. A review of the overflow of inflatable flexible membrane dams. Aust. Civ. Eng. Trans. 1997, 39, 107-116.

5. Wu, P.-H.; Plaut, R. Analysis of the vibrations of inflatable dams under overflow conditions. Thin-Walled Struct. 1996, 26, 241-259. [CrossRef]

6. Chanson, H.; Tam, P.W.M. Discussion and Closure: Use of Rubber Dams for Flood Mitigation in Hong Kong. J. Irrig. Drain. Eng. 1998, 124, 181-184. [CrossRef]

7. Chanson, H. Hydraulics of rubber dam overflow: A simple design approach. In Proceedings of the 13th Australasian Fluid Mechanics Conference, Melbourne, Australia, 13-18 December 1998; pp. 255-258.

8. Hager, W.H. Critical flow condition in open channel hydraulics. Acta Mech. 1985, 54, 157-179. [CrossRef]

9. Hager, W.H. Discussion of "Characteristics of Circular-Crested Weirs" by A.S. Ramamurthy and N.-D. Vo (1993, 119). J. Hydraul. Eng. 1994, 120, 1494-1495. [CrossRef]

10. Chanson, H.; Montes, J.S. Overflow Characteristics of Circular Weirs: Effects of Inflow Conditions. J. Irrig. Drain. Eng. 1998, 124, 152-162. [CrossRef]

11. Heidarpour, M.; Chamani, M. Velocity distribution over cylindrical weirs. J. Hydraul. Res. 2006, 44, 708-711. [CrossRef]

12. Bagheri, S.; Heidarpour, M. Overflow characteristics of circular-crested weirs. J. Hydraul. Res. 2010, 48, 515-520. [CrossRef]

13. Schmocker, L.; Halldórsdóttir, B.R.; Hager, W.H. Effect of Weir Face Angles on Circular-Crested Weir Flow. J. Hydraul. Eng. 2011, 137, 637-643. [CrossRef]

14. Naghavi, B.; Esmaili, K.; Yazdi, J.; Vahid, F.K. An experimental and numerical study on hydraulic characteristics and theoretical equations of circular weirs. Can. J. Civ. Eng. 2011, 38, 1327-1334. [CrossRef]

15. Cheraghi-Shirazi, N.; Kabiri-Samani, A.; Boroomand, B. Numerical analysis of rubber dams using fluid-structure interactions. Flow Meas. Instrum. 2014, 40, 91-98. [CrossRef]

16. Yuce, M.I.; Al-Babely, A.A.; Al-Dabbagh, M.A. Flow simulation over oblique cylindrical weirs. Can. J. Civ. Eng. 2015, 42, 389-407. [CrossRef]

17. Cheraghi-Shirazi, N.; Kabiri-Samani, A.; Boroomand, B. Flow field over the rubber dams based on fluid-structure interactions. J. Civ. Eng. 2017, 49, 141-144. [CrossRef]

18. Deardorff, J.W. A numerical study of three-dimensional turbulent channel flow at large Reynolds numbers. J. Fluid Mech. 1970, 41, 453-480. [CrossRef]

19. Pope, S.B. Turbulent Flows; Cambridge University Press: Cambridge, UK, 2000.

20. O'Neil, J.; Meneveau, C. Subgrid-scale stresses and their modelling in a turbulent plane wake. J. Fluid Mech. 1997, 349, 253-293. [CrossRef]

21. Smagorinsky, J. General circulation experiments with the primitive equations: I. The basic experiment. Mon. Weather Rev. 1963, 91, 99-164. [CrossRef]

22. Rodi, W.; Constantinescu, G.; Stoesser, T. Large Eddy Simulation in Hydraulic; CRC Press: Boca Raton, FL, USA, 2013.

23. DeLong, M. Two Examples of the Impact of Partitioning with Chaco and Metis on the Convergence of Additive-Schwarz Preconditioned FGMRES; Technical Report LA-UR-97-4181; Los Alamos National Laboratory: Los Alamos, NM, USA, 1997.

24. Hirt, C.; Nichols, B. Volume of fluid (VOF) method for the dynamics of free boundaries. J. Comput. Phys. 1981, 39, 201-225. [CrossRef]

25. Cabot, W.; Moin, P. Approximate Wall Boundary Conditions in the Large-Eddy Simulation of High Reynolds Number Flow. Flow Turbul. Combust. 2000, 63, 269-291. [CrossRef]

26. Korzekwa, D.A. Truchas-A multi-physics tool for casting simulation. Int. J. Cast Met. Res. 2009, 22, 187-191. [CrossRef]

27. Chu, C.-R.; Wu, Y.-R.; Wu, T.-R.; Wang, C.-Y. Slosh-induced hydrodynamic force in a water tank with multiple baffles. Ocean Eng. 2018, 167, 282-292. [CrossRef] 
28. Chu, C.-R.; Chung, C.-H.; Wu, T.-R.; Wang, C.-Y. Numerical analysis of free surface flow over a submerged rectangular bridge deck. J. Hydraul. Eng. 2016, 142. [CrossRef]

29. Chu, C.-R.; Lin, Y.-A.; Wu, T.-R.; Wang, C.-Y. Hydrodynamic force of circular cylinder close to the water surface. Comput. Fluids 2018, 171, 154-165. [CrossRef]

30. Wu, T.-R.; Vuong, T.-H.-N.; Lin, J.-W.; Chu, C.-R.; Wang, C.-Y. Three-Dimensional Numerical Study on the Interaction between Dam-Break Wave and Cylinder Array. J. Earthq. Tsunami 2018, 12, 1-35. [CrossRef]

31. Matthew, G.D. On the influence of the curvature, surface tension and viscosity on flow over round-crested weirs. Proc. Inst. Civil Eng. 1963, 25, 511-524. [CrossRef] 